\title{
A new species of Anaprostocteus Graham 1987 (Hymenoptera: Eulophidae) from Turkey
}

\author{
Lütfiye Gençer
}

Gençer, L. 2009: A new species of Anaprostocteus Graham 1987 (Hymenoptera: Eulophidae) from Turkey. — Entomol. Fennica 20: 225-227.

A new species, Anaprostocetus ankarensis Gençer is described from Kız1lcahamam, Ankara, Turkey. Diagnostic characters and line drawings of the new species are given.

L. Gençer, Cumhuriyet University, Faculty of Science and Art, Department of Biology,58140, Sivas, Turkey; E-mail: gencer@cumhuriyet.edu.tr

Received 6 February 2009, accepted 15 July 2009

\section{Introduction}

Anaprostocetus was erected by Graham (1987) with Anaprostocetus dehraensis Graham as the type species from Dehra Dun, India. In the same paper he transferred the European Entedon acuminatus Ratzeburg to Anaprostocetus. Anaprostocetus is widely distributed in the Holarctic region. La Salle (1994) recorded A. acuminatus from North America, Sheng (1995) described $A$. cenxiensis from China, and Narendran et al. (2005) described three new species, $A$. keralicus, $A$. areos, $A$. sringeriensis from India. Thus six species of Anaprostocetus Graham have been described world-wide: A. acuminatus (Ratzeburg), A. areos Narendran \& Fousi, A. cenxiensis Sheng, A. dehraensis Graham, A. keralicus Narendran \& Girish Kumar and A. sringeriensis Narendran \& Santhosh. Anaprostocetus acuminatus has been recorded from Cecidomyia salicis (Diptera: Cecidoymiidae), Euura atra, E. laeta (Hymenoptera: Tenthredinidae), Gypsonoma dealbana (Lepidoptera: Tortricidae), Yponomeuta malinellus (Lepidoptera: Yponomeutidae) and A. cenxiensis from Polylopha cassiola (Lepidoptera: Tortricidae) (Graham 1987, Noyes 2008). Hosts of other species are not known.

\section{Material and methods}

The single known specimen was swept from a pasture in Kizllcahamam, Ankara, Turkey and is deposited in the Insect Museum of Department of Biology, Faculty of Science and Art, Cumhuriyet University, Sivas, Turkey. Morphological terminology follows Graham (1987). Abbreviations used in descriptions are:

F1-F3: Funicular segments

POL: Postocellar distance

OOL: Distance between posterior ocellus and the eye

OD: Diameter of lateral ocellus

Cl-C3: Claval segments

SM: Submarginal vien

PM: Postmarginal vein

M: Marginal vein

S: $\quad$ Stigmal vein

\section{Taxonomy}

\subsection{Anaprostocetus ankarensis $\mathrm{sp} . \mathrm{n}$.}

Type material: Holotype female (on card), Turkey, Ankara, Kizılcahamam, 4046'97' 'N, 


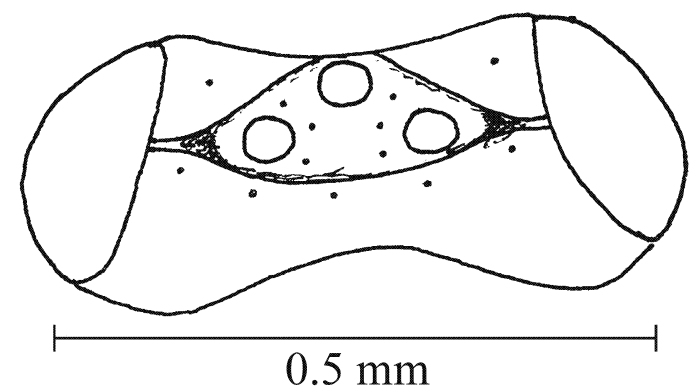

Fig. 1. Head of Anaprostocetus ankarensis sp. n., dorsal view.

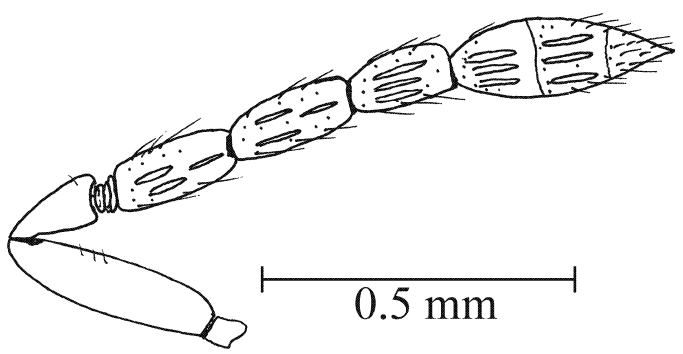

Fig. 2. Antenna of $A$. ankarensis sp. n.

$32^{\circ} 65^{\prime} 05^{\prime}$ 'E, 30.VII.2002, Collector, E. Sakaltaş, Entomology Museum of Department of Biology, Cumhuriyet University, Faculty of Science of Art.

Diagnosis: Clava 3 times as long as broad; claval length 0.8 times combined length of F2+F3; F1 nearly equal F2; pedicellus 0.6 times as long as F1. Gaster 3.4 times as long as broad; last tergite 1.5 times as long as broad. Forewing 2.3 times as long as broad.

Description: Holotype female. Length 3.7 $\mathrm{mm}$. Bright metallic green. Antennae brown with scape and pedicellus testaceous, anelli paler. Coxae concolorous with mesosoma; femora testaceous with outer side of basal part darker; tibiae and tarsi yellowish testaceous. Tegula pale yellow. Wing hyaline, venation pale brownish yellow. Gaster green with bronze tints on dorsal surface.

Head about as broad as mesoscutum, about 2.3 times as broad as long in dorsal view; POL 1.25 times OOL, OOL 1.6 times OD; ocellar triangle delimited by a distinct grooved line; each lateral ocellus connected to the adjacent eye by a grooved line (Fig. 1). Head in frontal view 1.2 times as wide as its length, shiny, with exces-

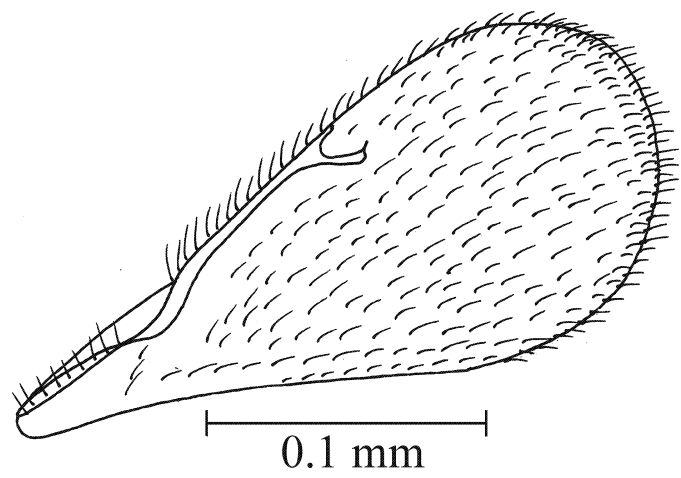

Fig. 3. Fore wing of $A$. ankarensis sp. n.

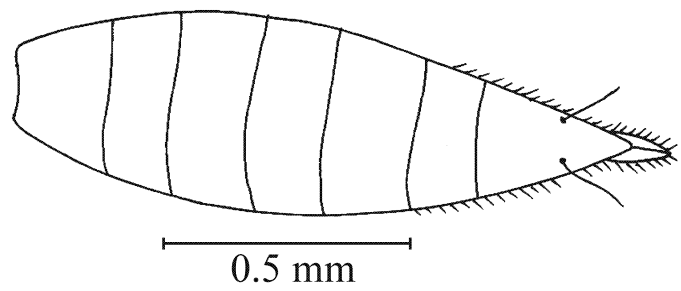

Fig. 4. Gaster of $A$. ankarensis sp. n., dorsal view.

sively fine reticulation; malar space 0.53 times length of eye, sulcus not curved. Antenna with scape shorter than an eye, reaching level of median ocellus, 4 times as long as broad; pedicellus plus flagellum 1.2 times breadth of mesoscutum; pedicellus 2 times as long as broad, 0.6 times as long as F1; anelli 3; funicle very slightly stouter than pedicellus, F1 and F2 subequal in length and F3 shorter, F1-2.6, F2-2.6, F3-2 times as long as broad; clava 3 times as long as broad, $\mathrm{C} 1$ and $\mathrm{C} 2$ as long as broad (Fig. 2).

Thorax 1.4 times as long as broad; pronotum 0.6 times length of mesoscutum; mid lobe of mesoscutum slightly broader than long, moderately convex, shiny, with fine engraved reticulation, median line distinct throughout, with 5 adnotular setae on each side. Scutellum 1.2 times as broad as long, 0.7 times length of mesoscutum; submedian lines about equidistant from each other and from sublateral lines, enclosing a space 2.1 times as long as broad, anterior pair of setae slightly behind the middle. Dorsellum 5 times as broad as long, moderately shiny, with extremely fine engraved reticulation. Propodeum medially slightly longer than dorsellum, having nearly isodiametric areoles; median carina raised, rather 
sharp, not expanding much posteriorly; paraspiracular carinae fine though distinct, curved; spiracles round, separated from metanotum with a distance lesser than half diameter of own; callus with 5 setae. Hind coxa 2 times as long as broad, with a distinct curved dorsal carina; hind femur 3.6 times as long as broad. Forewing 2.3 times as long as broad, reaching tip of gaster; costal cell distinctly shorter than M, SM with 9 dorsal setae, M 5 times as long as stigmal vein, its front edge with 15 setae; speculum open below (Fig. 3).

Gaster (Fig. 4) 3.4 times as long as broad, narrower than thorax; 1.3 times as long as head plus mesosoma, acuminate; last tergite 1.5 times as long as broad; ovipositor sheaths slightly exserted; tip of hypopygium at a little before half length of gaster.

Male: Unknown.

Host: Unknown.

Distribution: Turkey, Ankara, Kızllcahamam.

Etymology: The species epithet is after the state, Ankara, where the type locality is situated.

\section{Discussion}

Anaprostocetus is quite close to Aprostocetus, but can be recognized by having the following characters: hind coxa with a distinct carina along the dorsal margin; propodeum with strong curved paraspiracular carina; ocellar triangle surrounded by an impressed line or groove, and vertex with a large shallow fovea next to the lateral ocellus (Graham, 1987; La Salle, 1994). Following the key of Graham (1987) and Narendran et al. (2005) the new species is similar to A. keralicus and $A$. dehraensis in having clava distinctly shorter than combined length of F1+F2 and F1 nearly as long as F2. It can be separated from both of them by the following characters: clava 3 times as long as broad (in keralicus 3.5 times, in dehraensis 2.8 times); claval length 0.8 times combined length of $\mathrm{F} 2+\mathrm{F} 3$ (in keralicus 0.77 , in dehraensis 0.66 ); pedicellus 0.6 times as long as F1 (in keralicus 0.54 , in dehraensis 0.45 ); fore wing 2.3 times as long as broad (in keralicus 2.5); gaster 3.4 times as long as broad (in keralicus 3.6, in dehraensis 4.1); last tergite 1.5 times as long as broad (in keralicus 2.8, in dehraensis 2.0).

\section{References}

Graham, M. W. R. de V. 1987: A reclassification of the European Tetrastichinae (Hymenoptera:Eulophidae) with a revision of certain genera. - Bulletin of British Museum (Natural History) 55: 1-392.

La Salle, J. 1994: North American genera of Tetrastichinae (Hymenoptera:Eulophidae). - Journal of Natural History 28: 109-236.

Narendran, T. C., Fousi, K., Girish Kumar, P., Santhosh, S. \& Sinu, P. A. 2005: A taxonomic study of Anaprostocetus Graham (Hymenoptera:Eulophidae). - Oriental Insects 39: 273-280.

Noyes, J. S. 2008: Universal Chalcidoidea Database. [www document]. URL http://www.nhm.ac.uk/entomology/chalcidoids/index.html. (Site visited on 8 January 2009).

Sheng J. 1995: A new species of Tetrastichinae from China (Hymenoptera:Eulophidae, Tetrastichinae). - Entomologica Sinica 17: 21-24. 